This is a pre-print version of an article published in Population Studies - A Journal of Demography, doi: 10.1080/00324728.2016.1223336

Jona Schellekens

Department of Sociology and Anthropology

Hebrew University

Mount Scopus

Jerusalem 91905

Israel

E-mail: jona@mail.huji.ac.il

\title{
Early-Life Conditions and Adult Mortality Decline among Dutch Cohorts Born in 1812-1921
}

Short title: Early-life conditions and adult mortality

$$
\text { Jona Schellekens }{ }^{1} \text { and Frans van } \text { Poppel }^{2}
$$

${ }^{1}$ Hebrew University; ${ }^{2}$ Netherlands Interdisciplinary Demographic Institute 


\section{Early-life conditions and adult mortality decline among}

\section{Dutch cohorts born in 1812-1921}

Mounting evidence suggests that early-life conditions have an enduring effect on an individual's mortality risks as an adult. The contribution of improvements in early-life conditions to the overall decline in adult mortality, however, remains a debated issue. We provide an estimate of the contribution of improvements in early-life conditions to mortality decline after age thirty among Dutch cohorts born between 1812 and 1921. We use two proxies for early-life conditions: median height and early childhood mortality. We estimate that improvements in early-life conditions contributed more than five years or about a third to the rise in female life expectancy at age 30. Improvements in early-life conditions contributed almost three years or more than a quarter to the rise in male life expectancy at age 30. Height appears to be the more important of the two proxies for early-life conditions.

Keywords: adult mortality, early-life conditions, height, infant mortality, earlychildhood mortality 


\section{Early-life conditions and adult mortality decline among}

\section{Dutch cohorts born in 1812-1921}

\section{Introduction}

Mounting evidence suggests that early-life conditions have an enduring effect on an individual's mortality risks as an adult (e.g. Bengtsson and Mineau 2009). The contribution of improvements in early-life conditions to the overall decline in adult mortality, however, remains a debated issue. Whereas Costa (2004) and Crimmins and Finch (2006) argued that better early-life conditions made a major contribution to the decline in adult mortality, Barbi and Vaupel (2005) argued that period-specific influences were more important during the decline. While they admit that early-life factors may affect late-life mortality, they argue that the effect is modest.

Diet and exposure to infectious disease are two key early-life conditions linked to adult mortality. There is disagreement about the relative importance of a better diet and a decline in the exposure to infectious disease. Whereas Fogel and Costa (1997) focused primarily on chronic malnutrition, Crimmins and Finch (2006) were more concerned with the question of 'inflammation'. In the absence of information on the nutritional and disease environment in childhood, height and childhood mortality are often used as proxies. An individual's height is perhaps the single best indicator of nutritional and disease environment in childhood (Elo et al. 1992). Fogel and Costa (1997) argued that increased body size made a major contribution to the decline in adult mortality. Using data on Union Army veterans, Costa (2004) estimated that changes in frame size explain almost fifty percent of mortality decline among white men at older ages from 1914 to 1988. Finch and Crimmins (2004), on the other hand, argued that reductions in the exposure to 
infectious disease in childhood made a major contribution to the decline in adult mortality. Using mortality before age 15 as a proxy for exposure to infectious disease, Crimmins and Finch (2006) showed that in Sweden, France, Switzerland and England mortality at age 70-74 is well predicted by mortality before age 15 in the same cohort. However, using historical data from England and Wales, Finland, the Netherlands, and Sweden, Myrskylä (2010) found that shocks in early-life conditions, proxied by a cohort's infant mortality, are only weakly associated with a cohort's later mortality. He concluded that period factors are more important.

Costa (2004) and Crimmins and Finch (2006) may have overestimated the effect of early-life conditions. Costa (2004) used estimates of coefficients obtained in the cross-section to explain change over time, whereas Crimmins and Finch (2006) looked at macro-level correlations. Cross-sectional approaches to estimate longitudinal parameters may be biased (e.g. Mackenbach 2007; Maxwell and Cole 2007), whereas correlations that are based on aggregate data may be higher than correlations based on individual-level data (e.g. Ostroff 1993). Myrskylä (2010), on the other hand, may have underestimated the effect of early-life conditions because he only used the cohort's own mortality rates at ages 0 and 1-4 as a proxy for early-life conditions, and did not use anthropometric measures.

We will use two cohort proxies for early-life conditions, childhood mortality as well as an anthropometric measure. Instead of using only aggregate data, it combines individual-level data on both sides of the equation with aggregate data on the right side. It uses a random sample of individuals born in the Netherlands between 1812 and 1921 to analyze mortality decline among adults after age thirty until 2013. Female life expectancy at age 30 increased by almost fifteen years between cohorts born in 1812-29 and those born in 1910-21. We estimate that improvements in early- 
life conditions contributed more than five years, or about a third, to the rise in female life expectancy at age 30 . Male life expectancy at age 30 increased slightly over ten years between cohorts born in 1812-29 and those born in 1910-21. We estimate that improvements in early-life conditions contributed almost three years, or more than a quarter, to the rise in male life expectancy at age 30 . The much lower estimate for the effects of early-life improvements among men is likely to be the result of tobacco consumption. Height appears to be the more important of the two proxies for earlylife conditions.

\section{Early-life conditions and adult mortality}

\subsection{Exposure to infectious disease}

Exposure to infectious disease may have a long-term impact. There are few studies, however, of the impact of a specific infectious disease in childhood on adult health and mortality. People who were infected with Helicobacter pylori in childhood are more likely to develop gastritis and peptic ulcer in adulthood (Susser 2001).

Streptococcal infection has been linked to adult heart disease (Elo and Preston 1992). Brenes-Camacho and Palloni (2011) argued that malaria survivors in Costa Rica are more likely to die from stroke. Quaranta (2013) presented evidence for the impact of exposure to measles, scarlet fever and whooping cough epidemics in infancy on adult mortality in Sweden among cohorts born between 1813 and 1898. Cohen et al. (2010) only detected a very small effect of the 1918-1919 influenza pandemic on late-life mortality in 24 developed countries. But Myrskylä et al. (2013) found that exposure to the pandemic in the US did increase later mortality.

In the absence of information on exposure to infectious disease in childhood, many studies use infant and early-childhood mortality as proxies (e.g. Barker and 
Osmond 1986; Caselli and Capocaccia 1989; Ben-Shlomo and Smith 1991; Bengtsson and Lindström 2000; Catalano and Bruckner 2006; Crimmins and Finch 2006; Myrskylä 2010; Quaranta 2013). These studies support the hypothesis that exposure to childhood disease may cause permanent physical damage ("scarring") leading to fatal outcomes later in life.

Not all studies detected a significant effect of childhood mortality on adult mortality. Gagnon and Mazan (2009), for example, found little evidence for an effect of the infant mortality rate on mortality after age fifty in pre-industrial Québec. However, they did not study the effect of early-childhood mortality on adult mortality. Kermack et al. (1934) argued that the correlation between infant mortality and cohortspecific adult mortality is less clear-cut than the correlation between child mortality and cohort-specific adult mortality. But Crimmins and Finch (2006) and Floud et al. (2011, p. 257) observed that this depends on the country.

There are also processes, however, that may create a negative relationship between infectious disease in childhood and adult mortality: selection and acquired immunity (Elo and Preston 1992). According to the "hygiene hypothesis," disease exposure in early childhood may be essential for normal immune maturation (Strachan 1989; Folkerts et al. 2000). There is some evidence for selection and acquired immunity. Covering a period from 1907 to 1978 in Italy, Caselli and Capocaccia $(1989$, p. 152) reported that higher mortality early in life was associated with higher adult mortality before age 45 , whereas it was associated with lower mortality after age 45. Using historical time series for five European countries, Myrskylä (2010) found that high mortality at ages 1-4 may decrease mortality at ages up to 20 . 


\subsection{Malnutrition}

Malnutrition in childhood may also have a long-term impact. Height at the end of childhood is often used as an indicator of an individual's dietary history or gross nutrition. Height is inversely associated with coronary heart disease, stroke, and respiratory disease mortality among men and women. Whereas smoking related cancer mortality is not associated with height, the risk of death from cancer unrelated to smoking tends to increase with height, particularly for haematopoietic, colorectal and prostate cancers, except for stomach cancer mortality, which is inversely associated with height (Smith et al. 2000). Most studies report a negative correlation between height and adult mortality (e.g. Fogel 1994; Alter 2004, pp. 266-68). Su (2009), however, observed that being taller is related to a higher relative risk of mortality for Union Army veterans who survived past 1910.

There has been a tendency to explain changes in height primarily as the result of changes in the availability of food (Oxley 2003). Height, however, is really a measure of net nutrition, i.e. the balance between the supply of nutrients, physical exertion and disease (Fogel 1991, pp. 446-7; Elo and Preston 1992, p. 203; Alter 2004, p. 266). Bozzoli et al. (2009) reported evidence for a relationship between disease in early life and adult height among cohorts born in Western countries between 1950 and 1980 . They found that pneumonia was the most likely disease to compromise ultimate growth. But Öberg (2015) suspects that environmental conditions confounded their results. Voth and Leunig (1996) instigated the debate over the impact of smallpox on height. Oxley (2003), however, argued that the negative correlation between smallpox marks and height is not causational, both being the result of urban residence. Adair and Guilkey (1997) have shown that diarrhoeal disease reduces growth in childhood. There may also be reverse causality, however, 
malnutrition being a risk factor for infectious disease (Schaible and Kaufmann 2007). Thus, the two most-commonly used proxies for exposure to infectious disease and malnutrition, childhood mortality and height, respectively, may be correlated.

In the absence of anthropometric measures, some use an exogenous variable, such as food prices in early childhood. Bengtsson and Lindström (2000) and Quaranta (2013), for example, used rye prices as a proxy for malnutrition. They did not find any impact of the price of rye around birth on mortality at ages 55-79 in Southern Sweden in 1760-1894. Van den Berg et al. (2009) used wheat prices in the year of birth, but the effect on adult mortality was not significant among Danish cohorts born in 18731906. Perhaps, this result is not surprising, because in malnourished mothers, the quality and quantity of breast-milk is preserved at the expense of maternal health (Prentice et al. 1986).

Others have investigated the long-term effect of famines. A study of the Dutch 'Potato Famine' in the mid-1840s found higher rates of late-life mortality among cohorts born during the famine (Lindeboom et al. 2010). But Kannisto et al. (1997) did not find any evidence that famine in early childhood influenced mortality between ages 60 and 80 among cohorts born during the Great Finnish Famine of 1866-68. One possible explanation for the conflicting evidence of the long-term effect of famines on survival is that selection during famine altered the distribution of frailty across the population. Hence, Doblhammer et al. (2013) re-analyzed the Finnish data used by Kannisto et al. (1997). Simultaneously modeling the frailty distributions of cohorts, they showed that cohorts born during the Great Finnish Famine had a lowered life expectancy.

According to Barker (1995) prenatal exposure to malnutrition raises the risks of coronary heart disease. Ekamper et al. (2014) reported an effect of exposure to 
famine in early gestation on adult mortality up to the age of 63 years among those born during the 1944-1945 Dutch famine. No such effect was found for late gestation. But McEniry and Palloni (2010) found that exposure to malnutrition during late gestation had a significant effect on the risks of experiencing heart disease among 60to 74-year old Puerto Ricans.

\subsection{Living standards}

As living standards improve, exposure to infectious disease (see 2.1) and malnutrition (see 2.2) may decline. Hence, several studies have investigated the influence of fluctuations in living standards. Van den Berg et al. (2006) and van den Berg et al. (2009) used the gross domestic product (GDP) per capita around birth as a measure of living standards. The two studies reported a negative effect of GDP per capita around birth on adult mortality in the Netherlands and Denmark. Janssen et al. (2006) reported a mostly negative correlation of the GDP per capita prevailing at earlier ages with adult mortality in seven European countries.

\subsection{Adverse childhood socio-economic position}

Adverse childhood socio-economic position may also influence adult mortality (e.g. Hayward and Gorman 2004). It may influence adult mortality either through exposure to infectious agents and malnutrition or through adult socio-economic position. In a study of Dutch cohorts born in 1850-1922, van Poppel and Liefbroer (2005) used the father's occupation to measure childhood socio-economic position, but observed no effect on survival in later life. In a larger study of Dutch cohorts born in 1812-1912, however, van den Berg et al. (2006) found that women from a higher socio-economic background had significantly lower mortality in adulthood. 


\subsection{Inconsistent results}

Although many studies have reported that early-life conditions affect an individual's mortality risk as an adult, there are also studies that did not find such an effect. Regarding infant and early-childhood mortality, one possible explanation is that some used infant mortality as a proxy for exposure to infectious disease, whereas others used early-childhood mortality (see section 2.1). Another possible explanation is that the exposure to infectious disease raises adult mortality through scarring, while lowering it through selection and acquired immunity. Whether one effect is stronger than the other may depend on the causes of death prevalent in adulthood. The effect of height is known to vary depending on the cause of death (e.g. Smith et al. 2000).

Studies of the contribution of improvements in early-life conditions to the overall decline in adult mortality have also shown inconsistent results. Methodological inadequacies may account for some of the inconsistent results. A few studies used estimates of coefficients obtained in the cross-section to explain change over time (e.g. Costa 2004), whereas others have used time series (e.g. Crimmins and Finch 2006). Using childhood mortality rather than anthropometric measures as a proxy for early-life conditions may also have affected results (e.g. Myrskylä 2010). We will analyze adult mortality decline at the individual level as a function of two macro-level proxies for early-life conditions.

\section{Data and variables}

The data used in the analysis come from the Historical Sample of the Netherlands (HSN), Data Set Survival Dates Release 2013.01. The HSN is a national database with information on the complete life history of a half percent random sample $(78,102$ 
birth records) of men and women born in the Netherlands between 1812 -the first year for which vital registration is available for the whole country- and 1922. In all Dutch provinces, a random sample of births was drawn from the registration of births, which was stratified by period of birth and level of urbanization of the municipality (Mandemakers 2000).

Several previous studies used an earlier release (e.g. van Poppel and Liefbroer 2005; van den Berg et al. 2006; Lindeboom et al. 2010; Schenk and van Poppel 2011). The 2013 release includes a new version of the survival table which is based on information from the population registers until 30 April 302013.

The collection of death certificates for adults in the HSN has been uneven. Hence, our analysis is based on individuals born after 1812 in the provinces of Friesland, Overijssel, Utrecht and Zeeland, on individuals born after 1843 in the city of Rotterdam and on individuals born after 1863 in the rest of the country (van den Berg et al. 2006; Kok et al. 2009). For some individuals there is no date of death, but only a last date of observation. Migration is a major cause of censoring (Mandemakers 2000). In our analysis there are 29,220 individuals who are known to have survived until age 30, at least. For 1,936 individuals (6.6 percent) only a date of last observation is available.

To determine the extent to which the HSN is representative for the whole country, we compared the HSN with unpublished cohort life tables constructed by Statistics Netherlands. Individuals were divided into ten-year cohort blocks. The number of individuals born in 1812-19 and 1920-21 is relatively small. Hence, these two cohort blocks were combined with the nearest cohort blocks, 1820-29 and 191019 , respectively. 
Figures 1 and 2 compare trends in cohort life expectancy at age 30 for women and men, respectively, in the HSN with those in official statistics. Our estimates indicate that life expectancy at age 30 among those born in 1812-29 was almost 35 years for women and 34 for men. By 1910-21 life expectancy for women had risen to almost 50 and slightly over 44 for men. Statistics Netherlands did not publish life expectancy at age 30 for cohorts born before 1830. Thus, the comparison is limited to those born after 1830 . Whereas there are few signs of bias among women, even among those born before 1863, the HSN consistently overestimates male life expectancy. Not all provinces are equally well represented in the HSN, however. To the extent that regional differences in mortality among men were larger than those among women, our estimates of male life expectancy may be biased.

Life expectancy at age 30 rose much less among men than among women (see also Wolleswinkel-van den Bosch et al. 1998). Tobacco consumption was the main contributor to the increasing gap between men and women in life expectancy. The smoking epidemic in the Netherlands started among men born around 1850 and among women born after 1900 (Janssen and van Poppel 2015).

[Figures 1 and 2 about here]

In the multivariate analysis, the dependent variable is mortality after age 30. This decision is based on the observation that the age pattern of survival after age 30 does not change much over time. Mortality after age 30 is modeled as a function of place of birth, socio-economic position in childhood, age, period, and proxies for early-life conditions.

We used two cohort life table functions, infant mortality $\left({ }_{1} \mathrm{q}_{0}\right)$ and earlychildhood mortality $\left({ }_{4} q_{1}\right)$, as proxies for exposure to infectious disease in early childhood by year of birth. In the HSN a special effort was made to collect all death 
certificates of individuals who died in childhood (Mandemakers 2000, p. 161). We estimated the life table functions from the HSN for each single year of birth. Our estimates for infant and early-childhood mortality are not sex-specific. There is no significant difference between boys and girls in mortality between the first and fifth birthday in the HSN database, the odds for a female dying relative to those of a male being 0.978 . But, there is a very significant difference in infancy, the odds ratio for a female dying being only 0.803 . Of course, even today female infants have lower odds of dying. Trends in infant mortality, however, are nearly identical for both sexes. Hence, we pooled boys and girls to obtain better estimates of annual infant mortality rates. Figure 3 shows trends in infant mortality $\left({ }_{1} q_{0}\right)$ and early-childhood mortality $\left({ }_{4} \mathrm{q}_{1}\right)$. Infant and early-childhood mortality started to decline in the $1860 \mathrm{~s}$, but the decline slowed down in the 1870 s. In the 1880 s the rate of decline increased again.

[Figure 3 about here]

We used the median height of conscripts as a proxy for the nutritional status of single-year birth cohorts by attributing the median height of conscripts measured in year $t$ to all those born in year $t-19$. Brinkman, Drukker, and Slot (1988) published a time series of median heights (in mm) of Dutch conscripts from 1863 to 1940 . These data were revised by Mandemakers and van Zanden (1993) by correcting for bias due to the under-representation of men from more wealthy families and by adjusting for small changes over time in the age at measurement. Drukker and Tassenaar (1997) extended the time series further back in time to include the conscription years 18181863. There is no comparable source of information on the height of women. Among prisoners born between 1815 and 1865, however, trends in the height of men and women were similar (de Beer 2010). Data from England for criminals born between 1812 and 1857 also show similar trends in the height of men and women (e.g. 
Johnson and Nicholas 1995). A study of trends in sex differentials in adult height in the UK among individuals born between 1910 and 1942 also shows similar trends for men and women, even though there were greater increases for men than for women (Kuh et al. 1991). If among individuals born in the second half of the nineteenth century in the Netherlands there were also greater increases for men than for women, then we may have underestimated the effect of height on the mortality of adult women, although this should affect our predicted values of adult female life expectancy to a lesser extent.

There is also a genetic component to height (Elo and Preston 1992, p. 202). We do not model the mortality experience of individuals as a function of their individual adult height, however, but as a function of the median adult height of men born in the same year as these individuals. Genetics is less likely to explain the increase in height across cohorts.

Figure 3 shows that median height declined among those born before the 1840s and started to increase again among those born in the 1850s. The cohort of 1860-69 was the first to be taller than the cohort born in 1812-29. The continuous series of height data ends in 1921, because of World War II. Hence, the analysis is limited to people born in 1812-1921.

There are regional differences in height (Drukker and Tassenaar 1997; Fredriks et al. 2000). Hence, we control for province of birth. The variables indicating birth in the provinces of North and South Holland do not include the two largest cities, Amsterdam and Rotterdam. Two additional variables indicate birth in these cities. There are no missing values for place of birth.

There are also regional differences in infant and early-childhood mortality. In urban areas, for example, mortality was higher (e.g. van Poppel et al. 2005). Some 
infectious diseases were more prevalent in certain provinces. Malaria, for example, did not disappear from the coastal marshes in the Netherlands until the 1950s (Knottnerus 2002). We do not have enough cases for reliable estimates of infant and early-childhood mortality by province. Hence, to show that there were regional differences, we have divided the eleven provinces of the Netherlands into four regions: the North (Groningen, Friesland and Drenthe); the East (Overijssel and Gelderland); the West (Utrecht, North and South Holland and Zeeland); and the South (North Brabant and Limburg). Figures 4(a) and 4(b) show trends in infant and earlychildhood mortality for each region by cohort block. They show that mortality was highest in the more urban West. They also show that differences in mortality were not constant over time. Hence, we will add interactions between infant and/or earlychildhood mortality and place of birth.

[Figures 4(a) and 4(b) about here]

Adverse childhood socio-economic position may influence adult mortality. After controlling for exposure to infectious agents and malnutrition, it may influence adult mortality through poor education (e.g. Hayward and Gorman 2004). We used the occupation of the father at birth to measure childhood socio-economic position. To define socio-economic groups, we used the Social Power scheme (hereafter SOCPO) developed by van de Putte and Miles (2005). The fundamental organizational principle of their scheme is the potential to influence one's destiny through control of resources. We split their fourth category into farmers and others. Hence the categories used in the analyses are:

1. Unskilled workers (reference category);

2. Semi-skilled workers and the micro-scale self-employed;

3. Manual skilled workers; and supervisors of semi- and unskilled workers; 
4a. Manual super-skilled and non-manual skilled workers; supervisors of skilled workers; and local businessmen;

4b. Farmers;

5. Non-manual super-skilled workers; supra-local businessmen; executives and those with general policy tasks; and nobility;

6. Without occupation; and unknown.

Conditions in adulthood also influence mortality. Without a control for changes in these conditions, we may over-estimate the influence of early-life conditions on adult mortality. To control for unidentified exogenous period influences on adult mortality, we coded the person-years for period. The coding for period was composed of 31 blocks, the first block (1842-59) being the reference category. The blocks span five years, except for the first and last block (2005-13), because they contain fewer deaths.

\section{Analytic Approach}

A discrete-time hazard model is used to assess the effects of the independent variables on survival after age thirty. We have assumed that the hazard is constant within annual intervals. We estimated discrete-time hazard models using logistic regression. This kind of analysis can accommodate two common features of event histories: censored data and time-varying covariates (Allison 2010, pp. 236-240).

The dependent variable in the statistical model is the annual log odds of dying. The unit of analysis is the "person-year"; that is, each person contributes as many units to the analysis as the number for which he/she is observed. Person-years below age thirty were omitted from the analysis. Records were right-censored at the end of 
April 2013. Women and men contributed 620,509 and 579,238 person-years, respectively, to the analysis.

The logistic regression model assumes that the observations are independent, but because observations from the same subject are likely to be correlated, this is not usually a reasonable assumption. We do not model the probability that an individual will die in year $t$, however, but the conditional probability that an individual will die in year $t$ given that the individual is still alive in year $t-1$. In such a case there is no need to correct standard errors for clustering in individuals (Singer and Willett 2003, p. 384).

There is synergy between disease and malnutrition in the stunting of growth. Thus, adult height is not only a function of diet, but also of infectious disease burden. Hence, our two indicators of the influence of early-life conditions, height and earlychild mortality, are correlated. The high level of collinearity between the cohort proxies is likely to result in unstable estimates. One solution is to omit one of the cohort proxies from the analysis. But the omission of variables may create another problem: endogeneity. Collinearity between the cohort proxies, however, does not affect the coefficients of other variables (Allison 1999, p. 48). Hence, we will focus on the combined effect of the cohort proxies. Although not a remedy for collinearity, a relatively large sample will dampen the inflation of variances caused by collinearity (O’Brien 2007, p. 675).

Previous studies often de-trended the mortality time series to prevent bias by unobserved factors driving the trends. Studies that correlate fluctuations, however, assume that the determinants of short-term fluctuations in mortality are the same as those of secular trends in mortality (e.g. Myrskylä 2010, p. 823). We did not want to make such a strong assumption in a study of the decline in mortality. Moreover, we 
believe to have left out few unobserved factors driving trends, because major trends in the predicted series of life expectancy at age 30 resemble those in the observed series (see below). Few unobserved factors driving trends having been left out, it is not imperative to de-trend time series.

\section{Results}

Table 1 presents descriptive statistics of the variables used in the multivariate analysis. Tables 2 and 3 each present two models of adult mortality above age thirty, two for each sex. Coefficients are presented as odds ratios or exponents of the raw logistic coefficients. The odds ratios are multiplicative effects on the odds of dying in any one-year interval. A coefficient of 1.00 represents no statistical effect, a coefficient greater than 1.00 represents a positive effect, and a coefficient less than 1.00 represents a negative effect on the odds.

[Table 1 about here]

\subsection{Women}

The first model in Table 2 presents the results for women without interactions. Childhood socio-economic position does not have a significant effect on adult female mortality. But place of birth does have a significant effect. Women born in the coastal provinces, i.e. in Groningen, Friesland, North and South Holland, excluding Amsterdam and Rotterdam, or Zeeland, had significantly lower mortality than women born in the inland province of Utrecht.

[Table 2 about here]

After controlling for change in the distribution of childhood socio-economic position across cohorts, median height has a significant and negative effect on 
mortality after age thirty. Contrary to Kermack et al. (1934), infant mortality $\left({ }_{1} q_{0}\right)$ has a significant and positive effect, but early-childhood mortality $\left({ }_{4} \mathrm{q}_{1}\right)$ does not have a significant effect on adult mortality.

The hypothesis, that net of nutrition exposure to infectious agents mainly affects adult mortality through scarring, rather than selection and acquired immunity, is consistent with our data. The proxies for early-life conditions are correlated, however. Hence, their coefficients should be interpreted with care. In this sub-section we consider their combined effect.

The effect of early-life conditions may vary from one place of birth to the other (see Figures 4(a) and 4(b)). Hence, the second model adds interactions between early-childhood mortality $\left({ }_{4} \mathrm{q}_{1}\right)$ and place of birth. The addition of interactions between place of birth and height and place of birth and infant mortality did not result in a significant change in the log-likelihood. Hence, these have been omitted.

Figure 5 presents observed and predicted values of cohort life expectancy at age 30. A comparison of the observed series (thin line) with the predicted series (thick line) in the second model indicates the extent to which the regression model is able to predict the timing of the onset and pace of adult female mortality decline.

[Figure 5 about here]

A simple way to interpret the regression coefficients of the cohort proxies is to simulate what life expectancy at age 30 would have been under constant early-life conditions. Hence, we computed a predicted series of cohort life expectancy at age 30 that factors out improvements in early-life conditions that occurred after the birth cohort of 1812-29 from the predicted series of cohort life expectancy at age 30 in the second model. We call the result a 'counterfactual-predicted series' (thick dotted line in Figure 5). For each cohort, age-specific mortality rates were simulated by 
computing the predicted probability for each woman that she will die at age $x$. These probabilities were summarized to obtain the predicted number of deaths for age group $x$. To obtain predicted age-specific mortality rates, the predicted number of deaths in age group $x$ was divided by the observed number of person-years in age group $x$.

If not for improved early-life conditions, our model predicts that life expectancy at age 30 would have increased less among women born after 1860. If median height and early-childhood mortality had not changed after 1812-29, then the second model predicts that life expectancy at age 30 among those born in 1910-21 would have been 44.3 instead of 49.6 , a difference of 5.3 years. Thus we estimate that about a third of the decline in female adult mortality is associated with increased height and a decline in early-childhood mortality.

Figure 5 indicates that change in early-life conditions did not improve adult female life expectancy among cohorts born before the 1860s, even though height started to increase among those born in the 1840s. There are two reasons for this. First, we hold early-life conditions constant at their initial level among those born in 1812-29. And second, initially height declined.

\subsection{Men}

The first model in Table 3 presents the results for men without interactions. Men whose fathers were farmers had significantly lower mortality in adulthood. Gagnon and Bohnert (2012) and Preston et al. (1998) also found evidence for lower mortality in adulthood among Canadian and African-American men born on farms. Similar to our results they did not find such an effect for women. It is not clear how a similar early-life environment could have produced different physiological effects on boys compared to girls (Preston et al. 1998, p. 1242). One explanation could be that males 
who grew up on farms were more likely to become farmers themselves, an occupation that is associated with low mortality, whereas females who grew up on farms were less likely to become farmer's wives (Preston et al. 1998, p. 1239). Except for the inland province of Gelderland, the effect of place of birth resembles that for women.

[Table 3 about here]

Height has a significant effect. Males who belong to taller cohorts had lower mortality in adulthood. Infant mortality $\left({ }_{1} \mathrm{q}_{0}\right)$ and early-childhood mortality $\left({ }_{4} \mathrm{q}_{1}\right)$, on the other hand, do not have a significant effect on adult mortality. Due to collinearity, however, variables that appear to have weak effects, may actually have quite strong effects as a group (Allison 1999, p. 48). Hence, in this sub-section we only consider the combined effect of the proxies for early-life conditions.

The effect of early-life conditions may vary from one place of birth to the other (see Figures 4(a) and 4(b)). Hence, the second model adds interactions between early-childhood mortality and place of birth. The addition of interactions between place of birth and height and place of birth and infant mortality did not result in a significant change in the log-likelihood. Hence, these have been omitted.

Figure 6 presents observed and predicted values of cohort life expectancy at age 30. A comparison of the observed series (thin line) with the predicted series (thick line) in the second model indicates the extent to which the regression model is able to predict the timing of the onset and pace of adult mortality decline among men.

[Figure 6 about here]

Figure 6 also presents a counterfactual-predicted series (thick dotted line). If not for improved early-life conditions, the second model predicts that life expectancy at age 30 would have increased less among men born after 1860 and even have declined among those born after 1890, possibly as a result of increased tobacco 
consumption. The omission of tobacco consumption may have biased our estimates of the coefficients of the proxies for early-life conditions among men. If median height and early-childhood mortality had not changed after 1812-29, then our model predicts that life expectancy at age 30 among those born in 1910-21 would have been 41.0 instead of 43.9, a difference of 2.9 years. Thus we estimate that more than a quarter of the decline in male adult mortality is associated with increased height and a decline in early-childhood mortality.

\subsection{The relative contribution of height and childhood mortality}

Height at the end of childhood is often used as an indicator of an individual's dietary history. Height, however, is also a function of infectious disease history. Moreover, malnutrition is a risk factor for infectious disease (see section 2.2). Thus, our two proxies for exposure to infectious disease and malnutrition, early-childhood mortality and height, respectively, are correlated. Although not a remedy for collinearity, a relatively large sample will dampen the inflation of variances caused by collinearity (O’Brien 2007, p. 675). Hence, this sub-section investigates which of the proxies for early-life factors is most important.

Figure 5 presents a counterfactual-predicted series for women that only assumes constant height (thin dotted line). This counterfactual-predicted series is closer to the counterfactual-predicted series that assumes constant early-life conditions (thick dotted line) than it is to the predicted series of cohort life expectancy at age 30 (thick solid line). This suggests that increased height made a larger contribution to the decline in female adult mortality than did the decline in infant and early-childhood mortality. 
Figure 6 presents a counterfactual-predicted series for men that only assumes constant height (thin dotted line). This counterfactual-predicted series is much closer to the counterfactual-predicted series that assumes constant early-life conditions (thick dotted line) than it is to the predicted series of cohort life expectancy at age 30 (thick solid line). Thus, increased height made a much larger contribution to the decline in male adult mortality than did the decline in childhood mortality.

\section{Conclusion and discussion}

The contribution of improvements in early-life conditions to the decline in adult mortality remains a much debated issue. We used a fairly large sample to estimate the contribution of improvements in early-life conditions to mortality decline after age thirty among Dutch cohorts born between 1812 and 1921 . We estimate that improvements in early-life conditions contributed more than five years, or about a third, to the rise in female life expectancy at age 30 between cohorts born in 1812-29 and 1910-21. Improvements in early-life conditions contributed almost three years, or more than a quarter, to the rise in male life expectancy at age 30 . Thus, our estimates are closer to those of Costa (2004) than to those of Myrskylä (2010).

There is also disagreement about the relative importance of a better diet and a decline in the exposure to infectious disease. Height is often used as a proxy for chronic malnutrition, whereas childhood mortality is often used as a proxy for the exposure to infectious disease, even though both proxies are a function of diet as well as exposure to infectious disease. Our results suggest that increased height made a larger contribution. One possible explanation for the smaller contribution of infant and early-childhood mortality is that selection and acquired immunity partly cancel the effect of scarring. 
In our models mortality change is driven only by early-life conditions and period mechanisms, ignoring the role of later-life cohort factors, such as tobacco consumption. To the extent that these later-life cohort factors are not correlated with our proxies for early-life conditions, the period dummy variables are not net of all cohort influences. The omission of these later-life cohort factors, however, may also have caused bias in our estimates of the coefficients of the proxies for early-life conditions. Tobacco consumption is likely to influence our results for men in particular, who tended to smoke more. In the Netherlands the effects of smoking on sex differences in mortality are known to have been relatively large (Valkonen and van Poppel 1997). Janssen and van Poppel (2015) have shown that smoking is a cohort effect among those born in the nineteenth century, but also a period effect among those born in the twentieth century. Unfortunately, we were unable to control for tobacco consumption or a proxy for it, such as lung-cancer mortality rates, for all cohorts in each year (Preston, Glei and Wilmoth 2010). To the extent that trends in tobacco consumption are correlated with trends in height and early-childhood mortality, we may have underestimated the size of the contribution of improvements in early-life conditions to the decline in male adult mortality. It is less likely that we underestimated the size of the contribution of improved early-life conditions to the decline in female adult mortality as a result of tobacco consumption. The estimated loss in life expectancy at age 35 in 1970-89 attributable to smoking was less than half a year, as opposed to almost four years among men (Valkonen and van Poppel 1997, p. 304).

In the Netherlands height has been shown to be a function of real income (Jacobs and Tassenaar 2004). To the extent that the increase in living standards in early childhood contributed to adult mortality decline not only through exposure to 
infectious agents and malnutrition in early childhood, but also through other intermediate variables, our estimates of the coefficients of the proxies for nutrition and exposure to early-childhood disease may be biased. In such a case we are likely to have overestimated the effect of these proxies for early-life conditions. Education may be one such intermediate variable, because living standards in childhood may influence adult mortality through education. Trends in educational level in the Netherlands, however, do not resemble those in early-life conditions. Whereas earlylife conditions did not start to improve until the second half of the nineteenth century, elementary education, as measured by literacy, had already started to increase among women born more than half a century earlier. Moreover, illiteracy levels, as measured by the ability to sign one's name, among men declined much earlier than those of women, whereas the timing of the onset of the decline in mortality is similar for both sexes (Boonstra 2008, p. 135). Of course, it is possible that better education of women influenced adult mortality of their children through improved early-life conditions.

In the middle of the nineteenth century, the Dutch were among Europe's shortest people (Steckel 1995). The increase in height was spectacular and today the Dutch population is among the tallest in the world (Schönbeck et al. 2013). Thus, the contribution of improvements in early-life conditions to the decline in adult mortality in the Netherlands may have been larger than that in other countries.

\section{Notes}

1. Jona Schellekens is Louis \& Pearl Rose Professor in Medical Sociology at the Department of Sociology and Anthropology, Hebrew University, Mount Scopus, Jerusalem 91905, Israel. E-mail: jona@mail.huj.ac.il. Frans van Poppel is honorary 
fellow at the Netherlands Interdisciplinary Demographic Institute (NIDI/KNAW) in The Hague, Netherlands.

2. Earlier versions of this paper were presented at the 2013 annual meeting of the Population Association of America, New Orleans, and at the 2014 Dutch Demography Day, Utrecht. We would like to thank three anonymous reviewers for their comments.

\section{References}

Adair, Linda S., and D. K. Guilkey. 1997. Age-specific determinants of stunting in Filipino children, Journal of Nutrition 127: 314-320.

Allison, Paul D. 1999. Logistic Regression using the SAS ${ }^{\circledR}$ System: Theory and Application. Cary, NC: SAS Institute Inc.

Allison, Paul D. 2010. Survival Analysis using the SAS ${ }^{\circledR}$ System: A practical Guide. 2nd ed. Cary, NC: SAS Institute Inc.

Alter, George. 2004. Height, frailty, and the standard of living: Modelling the effects of diet and disease on declining mortality and increasing height, Population Studies 58(3): 265-279.

Barbi, Elisabetta, and James W. Vaupel. 2005. Comment on "Inflammatory exposure and historical changes in human life-spans", Science 308, 1743a.

Barker, David J. P. 1995. Fetal origins of coronary heart disease, British Medical Journal 311, 171-174. 
Barker, David J. P., and C. Osmond. 1986. Infant mortality, childhood nutrition, and ischaemic heart disease in England and Wales, Lancet 1986(i): 1077-1081.

Bengtsson, Tommy, and G. Broström. 2009. Do conditions in early life affect old-age mortality directly and indirectly? Evidence from 19th-century rural Sweden, Social Science \& Medicine 68(9): 1583-1590.

Bengtsson, Tommy, and Martin Lindström. 2000. Childhood misery and disease in later life: The effects on mortality in old age of hazards experienced in early life, Southern Sweden, 1760-1894, Population Studies 54(3): 263-277.

Bengtsson, Tommy, and Geraldine P. Mineau. 2009. Early-life effects on socioeconomic performance and mortality in later life: A full life-course approach using contemporary and historical sources, Social Science \& Medicine 68(9): $1561-1564$.

Ben-Shlomo, Y., and George Davey Smith. 1991. Deprivation in infancy or in adult life: Which is more important for mortality risk? Lancet 337: 530-534.

Boonstra, Onno. 2008. Functioneel analfabetisme in Nederland, 1775-1900 [Illiteracy in the Netherlands, 1775-1900], in Ineke Maas, Marco H. D. van Leeuwen and Kees Mandemakers (eds.), Honderdvijftig Jaar Levenslopen: De Historische Steekproef Nederlandse Bevolking. Amsterdam: Amsterdam University Press, pp. 129-149.

Bozzoli, Carlos, Angus Deaton, and Climent Quintana-Domeque. 2009. Adult height and childhood disease, Demography 46(4): 647-669.

Brenes-Camacho, Gilbert, and Alberto Palloni. 2011. Malaria survivors during early life, health at old age, and stroke mortality in Costa Rica, paper presented at the Annual Meeting of the PAA, Washington, DC. 
Brinkman, H.-J., J. W. Drukker, and B. Slot. 1988. Height and income: A new method for the estimation of historical income series, Explorations in Economic History 25(3): 227-264.

Caselli, Graziella, and Riccardo Capocaccia. 1989. Age, period, cohort and early mortality: An analysis of adult mortality in Italy, Population Studies 43(1): $133-153$.

Catalano, Ralph, and Tim Bruckner. 2006. Child mortality and cohort lifespan: A test of diminished entelechy, International Journal of Epidemiology 35(5): 1264 1269.

Cohen, Allan A., John Tillinghast, and Vladimir Canudas-Romo. 2010. No consistent effects of prenatal or neonatal exposure to Spanish Flu on late-life mortality in 24 developed countries, Demographic Research 22(20): 579-634.

Costa, Dora. 2004. The measure of man and older age mortality: Evidence from the Gould sample, Journal of Economic History 64(1): 1-22.

Crimmins, Eileen M., and Caleb E. Finch. 2006. Infection, inflammation, height, and longevity, Proceedings of the National Academy of Sciences 103(2): 498-503.

de Beer, Hans. 2010. Physical stature and biological living standards of girls and young women in the Netherlands, born between 1815 and 1865, History of the Family 15(1) 60-75.

Doblhammer, Gabriele, Gerard J. van den Berg, and L. H. Lumey. 2013. A reanalysis of the long-term effects on life of the Great Finnish Famine of 186668, Population Studies 67:(3) 309-322.

Drukker, J. W., and Vincent Tassenaar. 1997. Paradoxes of modernization and material well-being in the Netherlands during the nineteenth century, in Richard H. Steckel and Roderick Floud (eds.), Health and welfare during 
industrialization. Chicago and London: The University of Chicago Press, pp. $331-377$.

Ekamper, P., F. van Poppel, A. D. Stein, and L. H. Lumey. 2014. Independent and additive association of prenatal famine exposure and intermediary life conditions with adult mortality between age 18-63 years, Social Science \& Medicine 119: 232-239.

Elo, Irma T., and Samuel H. Preston. 1992. Effects of early-life conditions on adult mortality: A review, Population Index 58(2): 186-212.

Finch, Caleb E., and Eileen M. Crimmins. 2004. Inflammatory exposure and historical changes in human life-spans, Science 305: 1736-1739.

Finch, Caleb E., and Eileen M. Crimmins. 2005. Response to comment on "Inflammatory exposure and historical changes in human life-spans", Science 308: $1743 b$.

Floud, Roderick, Robert W. Fogel, Bernard Harris, and Sok Chul Hong. 2011. The Changing Body: Health, Nutrition, and Human Development in the Western World since 1700. Cambridge: Cambridge University Press.

Fogel, Robert W. 1991. Nutrition and the decline in mortality since 1700: Some preliminary findings, in Stanley L. Engerman and Robert E. Gallman (eds.), Long-Term Factors in American Economic Growth. Chicago: University of Chicago Press, pp. 439-556.

Fogel, Robert W. 1994. Economic growth, population theory, and physiology: The bearing of long-term processes on the making of economic policy, American Economic Review 84(3): 369-395. 
Fogel, Robert W., and Dora L. Costa. 1997. A theory of technophysio evolution, with some implications for forecasting population, health care costs, and pension costs, Demography 34(1): 49-66.

Folkerts, Gert, Gerhard Walzl, and Peter J. M. Openshaw. 2000. Do common childhood infections 'teach' the immune system not to be allergic? Immunology Today 21(3) 118-120.

Fredriks, A. Miranda, Stef van Buuren, Ruud J. F. Burgmeijer, Joanna F. Meulmeester, Roelien J. Beuker, Emily Brugman, Machteld J. Roede, S. Pauline Verloove-Vanhorick, and Jan-Maarten Wit. 2000. Continuing positive secular growth change in the Netherlands 1955-1997, Pediatric Research 47(3): 316-323.

Gagnon, Alain, and Nora Bohnert. 2012. Early life socioeconomic conditions in rural areas and old-age mortality in twentieth-century Quebec, Social Science \& Medicine 75: 1497-1504.

Gagnon, Alain, and Ryan Mazan. 2009. Does exposure to infectious diseases in infancy affect old-age mortality? Evidence from a pre-industrial population, Social Science \& Medicine 68: 1609-1616.

Hayward, Mark D., and Bridget K. Gorman. 2004. The long arm of childhood: The influence of early-life social conditions on men's mortality, Demography 41(1): 87-107.

Jacobs, Jan, and Vincent Tassenaar. 2004. Height, income, and nutrition in the Netherlands: The second half of the $19^{\text {th }}$ century, Economic and Human Biology 2(2): 181-195.

Janssen, Fanny, Anton E. Kunst, Johan P. Mackenbach. 2006. Association between gross domestic product throughout the life course and old-age mortality across 
birth cohorts: Parallel analyses of seven European countries, 1950-1999, Social Science \& Medicine 63: 239-254.

Janssen, Fanny, and Frans van Poppel. 2015. The adoption of smoking and its effect on the mortality gender gap in Netherlands: A historical perspective, BioMed Research International, Article ID 370274.

Johnson, Paul, and Stephen Nicholas. 1995. Male and female living standards in England and Wales, 1812-1867: Evidence from criminal height records, Economic History Review 48(3): 470-481.

Kannisto, Väinö, Kaare Christensen, and James W. Vaupel. 1997. No increased mortality in later life for cohorts born during famine, American Journal of Epidemiology 145(11): 987-994.

Kermack, W. O., A. G. McKendrick, and P. L. McKinlay. 1934. Death rates in Great Britain and Sweden: Some regularities and their significance, Lancet 1: 698703.

Knottnerus, Otto S. 2002. Malaria around the North Sea: A survey, in Gerold Wefer, Wolfgang H. Berger, Karl-Ernst Behre, and Eynstein Jansen (eds.), Climatic development and history of the North Atlantic realm: Hanse Conference report. Berlin and Heidelberg: Springer-Verlag, pp. 339-353.

Kok, Jan, Kees Mandemakers, and Hilde Bras. 2009. Van geboortebank tot collaborator: Een reflectie op twintig jaar dataverzameling en onderzoek met de HSN [From a database of births to a collaboratory. A reflection on twenty years of data collection and research with the HSN dataset], Tijdschrift voor Sociale en Economische Geschiedenis 6(4): 3-36.

Komlos, John. 1993. The secular trend in the biological standard of living in the United Kingdom, 1730-1860, Economic History Review 46(1): 115-144. 
Kuh, D.L., C. Power, and B. Rodgers. 1991. Secular trends in social class and sex differences in adult height, International Journal of Epidemiology 20(4): 1001-1009.

Lindeboom, Maarten, France Portrait, and Gerard J. van den Berg. 2010. Long-run effects on longevity of a nutritional shock early in life: The Dutch Potato Famine of 1846-1847, Journal of Health Economics 29(5): 617-629.

Lynch, John W., George A. Kaplan, Richard D. Cohen, Jussi Kauhanen, Thomas W. Wilson, Nicholas L. Smith, and Jukka T. Salonen. 1994. Childhood and adult socioeconomic status as predictors of mortality in Finland, The Lancet 343: 524-527.

Mackenbach, Johan P. 2007. Commentary: Did Preston underestimate the effect of economic development on mortality? International Journal of Epidemiology 36(3): 496-497.

Mandemakers, Kees. 2000. The Netherlands: Historical Sample of the Netherlands, in P. Kelly Hall, R. McCaa and G. Thorvaldsen (eds.), Handbook of International Historical Microdata for Population Research. Minneapolis: Minnesota Population Center, pp. 149-177.

Mandemakers, Kees, and J. L. van Zanden. 1993. The height of conscripts and national income: Apparent relations and misconceptions, Explorations in Economic History 30(1): 81-97.

Maxwell, Scott E., and David A. Cole. 2007. Bias in cross-sectional analyses of longitudinal mediation, Psychological Methods 12(1): 23-44.

McEniry, Mary, and Alberto Palloni. 2010. Early life exposures and the occurrence and timing of heart disease among the older adult Puerto Rican population, Demography 47(1): 23-43. 
Myrskylä, Mikko. 2010. The relative effects of shocks in early- and later-life conditions on mortality, Population and Development Review 36(4): 803-829.

Myrskylä, Mikko, Neil K. Mehta, and Virginia W. Chang. 2013. Early life exposure to the 1918 influenza pandemic and old-age mortality by cause of death, American Journal of Public Health 103(7): e83-e90.

Öberg, Stefan. 2015. The direct effect of exposure to disease in early life on the height of young adult men in southern Sweden, 1814-1948, Population Studies 69(2): 179-199.

O’Brien, Robert M. 2007. A caution regarding rules of thumb, Quality and Quantity 41(5): 673-690.

Ostroff, Cheri. 1993. Comparing correlations based on individual-level and aggregated data, Journal of Applied Psychology 78(4): 569-582.

Oxley, Deborah. 2003. 'The seat of death and terror': Urbanization, stunting, and smallpox, Economic History Review 56, 623-656.

Prentice, Andrew, Alison Paul, Ann Prentice, Alison Black, Tim Cole, and Roger Whitehead. 1986. Cross-cultural differences in lactational performance, in Margit Hamosch and Armond S. Goldman (eds.), Human Lactation 2: Maternal and Environmental Factors. New York: Plenum Press, pp. 13-44.

Preston, Samuel H., Dana A. Glei, and John R. Wilmoth. 2010. A new method for estimating smoking-attributable mortality in high-income countries, International Journal of Epidemiology 39(2): 430-438.

Preston, Samuel H., Mark E. Hill, and Greg L. Drevenstadt. 1998. Childhood conditions that predict survival to advanced ages among African-Americans, Social Science \& Medicine 47, 1231-1246. 
Quaranta, Luciana. 2013. Scarred for life: How conditions in early life affect socioeconomic status, reproduction and mortality in Southern Sweden, 18131968, Lund Studies in Economic History 59.

Schaible, Ulrich E., and Stefan H. E. Kaufmann. 2007. Malnutrition and infection: Complex mechanisms and global impacts, PLoS Medicine 4(5): 806-812.

Schenk, Niels, and Frans van Poppel. 2011. Social class, social mobility and mortality in the Netherlands, 1850-2004, Explorations in Economic History 48(3): 401417.

Schönbeck, Yvonne, Henk Talma, Paula van Dommelen, Boudewijn Bakker, Simone E. Buitendijk, Remy A. HiraSing, and Stef van Buuren. 2013. The world's tallest nation has stopped growing taller: the height of Dutch children from 1955 to 2009, Pediatric Research 73(3): 371-377.

Singer, Judith D., and John B. Willett. 2003. Applied Longitudinal Data Analysis: Modeling Change and Event Occurrence. Oxford: Oxford University Press.

Smith, George Davey, Carole Hart, Mark Upton, David Hole, Charles Gillis, Graham Watt, and Victor Hawthorne. 2000. Height and risk of death among men and women: Aetiological implications of associations with cardiorespiratory disease and cancer mortality, Journal of Epidemiology and Community Health 54(2): 97-103.

Smith, Herbert L., William M. Mason, and Stephen E. Fienberg. 1982. Estimable functions of age, period, and cohort effects: More chimeras of the age-periodcohort accounting framework: Comment on Rodgers, American Sociological Review 47(6): 787-793.

Steckel, Richard H. 1995. New perspectives on the standard of living, Challenge 38(5): 12-18. 
Strachan, David P. 1989. Hay fever, hygiene, and household size, British Medical Journal 299: 1259-1260.

Su, Dejun. 2009. Risk exposure in early life and mortality at older ages: Evidence from Union Army veterans, Population and Development Review 35(2): 275295.

Susser, M. 2001. Commentary: The longitudinal perspective and cohort analysis, International Journal of Epidemiology 30(4): 684-687.

Valkonen, Tapani, and Frans van Poppel. 1997. The contribution of smoking to sex differences in life expectancy: Four Nordic countries and The Netherlands 1970-1989, European Journal of Public Health 7(3): 302-310.

van den Berg, Gerard J., Gabriele Doblhammer, and Kaare Christensen. 2009. Exogenous determinants of early-life conditions, and mortality later in life, Social Science \& Medicine 68(9): 1591-1598.

van den Berg, Gerard J., Maarten Lindeboom, and France Portrait. 2006. Economic conditions early in life and individual mortality, American Economic Review 96(1): 290-302.

van de Putte, Bart, and Andrew Miles. 2005. A social classification scheme for historical occupational data: Partner selection and industrialism in Belgium and England, 1800-1918, Historical Methods 38(2): 61-92.

van Poppel, Frans, Marianne Jonker, and Kees Mandemakers. 2005. Differential infant and child mortality in three Dutch regions, 1812-1909, Economic History Review 58(2): 272-309.

van Poppel, Frans, and Aart C. Liefbroer. 2005. Living conditions during childhood and survival in later life: Study design and first results, Historical Social Research 30(3): 265-285. 
Voth, Hans-Joachim, and Timothy Leunig. 1996. Did smallpox reduce height? Stature and the standard of living in London, 1770-1873, Economic History Review 49(3): 541-560.

Wolleswinkel-van den Bosch, Judith H., Frans W. A. van Poppel, Ewa Tabeau, and Johan P. Mackenbach. 1998. Mortality decline in the Netherlands in the period 1850-1992: A turning point analysis, Social Science \& Medicine 47(4): 429443. 
Table 1 Descriptive statistics for categorical variables used in the discrete-time hazard models of mortality: person-years of experience at ages 30+ by sex, Dutch cohorts born in 1812-1921

\section{Variable}

Period:

$1842-59$ (ref.)

1860-64

1865-69

1870-74

1875-79

1880-84

1885-89

1890-94

1895-99

1900-04

1905-09

1910-14

1915-19

1920-24

1925-29

1930-34

1935-39

1940-44

1945-49

1950-54

1955-59

1960-64

1965-69

1970-74

1975-79

1980-84

1985-89

1990-94

1995-99

2000-04

2005-13

Socio-economic status of father:

Unskilled workers (ref.)

Semi-skilled workers

Skilled workers

Farmers

Middle-class

Elite

Unknown

Place of birth:

Friesland

Groningen

Drenthe

Overijssel

Gelderland

Utrecht (ref.)

North Holland

Amsterdam

South Holland

Rotterdam

Zeeland

North Brabant

Limburg

Person years

\section{Percentage}

\section{Women $\quad \underline{\text { Men }}$}

$\begin{array}{ll}0.6 & 0.7\end{array}$

$0.3 \quad 0.4$

$0.4 \quad 0.5$

$0.5-0.5$

$0.6 \quad 0.6$

$0.7 \quad 0.8$

$0.8 \quad 0.9$

$1.1-1.2$

$\begin{array}{ll}1.8 & 1.9\end{array}$

$\begin{array}{ll}2.6 & 2.8\end{array}$

$3.2 \quad 3.4$

$3.9 \quad 4.0$

$4.5 \quad 4.6$

$5.1 \quad 5.2$

$5.8 \quad 6.0$

$6.5 \quad 6.7$

$\begin{array}{ll}6.9 & 7.1\end{array}$

$\begin{array}{ll}7.0 & 7.3\end{array}$

$\begin{array}{ll}7.0 & 7.2\end{array}$

$6.9 \quad 7.2$

$6.2-6.5$

$\begin{array}{ll}5.6 & 5.8\end{array}$

$5.0 \quad 5.0$

$4.3 \quad 4.1$

$3.6 \quad 3.2$

$\begin{array}{ll}3.6 & 2.4\end{array}$

$2.3 \quad 1.7$

$\begin{array}{ll}1.7 & 1.2\end{array}$

$\begin{array}{ll}1.1 & 0.7\end{array}$

$\begin{array}{ll}0.7 & 0.3\end{array}$

$0.3 \quad 0.2$

$30.3 \quad 32.3$

$10.8 \quad 10.4$

$19.1 \quad 18.0$

$13.5 \quad 14.3$

$17.9 \quad 16.9$

$\begin{array}{ll}4.9 & 4.7\end{array}$

$3.6 \quad 3.4$

$10.9-10.6$

$\begin{array}{ll}5.0 & 5.2\end{array}$

$2.6-2.8$

$8.1 \quad 8.1$

$9.0 \quad 9.8$

$\begin{array}{ll}7.6 & 7.5\end{array}$

$8.2 \quad 8.3$

$6.9-6.8$

$15.2 \quad 14.5$

$5.6 \quad 5.3$

$\begin{array}{ll}6.5 & 7.1\end{array}$

$9.8 \quad 9.4$

$4.5 \quad 4.8$

$620,509 \quad 579,238$ 
Table 2 Discrete-time hazard model of mortality at ages 30+: Dutch women born in 1812-1921

Variable

Early-life conditions:

$\begin{array}{ccccc}\text { Height } & 0.993 & 0.000 & 0.993 & 0.000 \\ { }_{1} \mathrm{q}_{0} \times 100 & 1.015 & 0.004 & 1.014 & 0.005 \\ { }_{4} \mathrm{q}_{1} \times 100 & 0.999 & 0.871 & 1.012 & 0.126\end{array}$

Place of birth:

Friesland

Groningen

Drenthe

Overijssel

Gelderland

Utrecht (ref.)

North Holland

Amsterdam

South Holland

Rotterdam

Zeeland

North Brabant

Limburg

Interaction of ${ }_{4} \mathrm{q}_{1}$ with place of birth:

Friesland

Groningen

Drenthe

Overijssel

Gelderland

Utrecht (ref.)

North Holland

Amsterdam

South Holland

Rotterdam

Zeeland

North Brabant

Limburg

Socio-economic status of father:

Unskilled workers (ref.)
Semi-skilled workers

Skilled workers

Farmers

Middle-class

$$
\text { Elite }
$$

Unknown

Age (linear)

Age (quadratic)

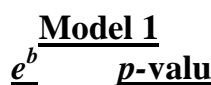

Model 2

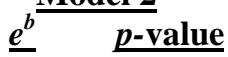

$\begin{array}{cccc}0.883 & 0.003 & 0.993 & 0.941 \\ 0.761 & 0.000 & 0.833 & 0.196 \\ 0.884 & 0.058 & 1.546 & 0.011 \\ 0.936 & 0.142 & 0.935 & 0.516 \\ 0.943 & 0.190 & 1.259 & 0.039 \\ 1.000 & - & 1.000 & - \\ 0.887 & 0.009 & 1.170 & 0.172 \\ 0.994 & 0.908 & 1.059 & 0.632 \\ 0.881 & 0.002 & 1.026 & 0.786 \\ 1.034 & 0.532 & 1.086 & 0.469 \\ 0.883 & 0.009 & 1.193 & 0.096 \\ 0.982 & 0.676 & 1.168 & 0.139 \\ 0.957 & 0.416 & 1.339 & 0.034\end{array}$

$0.989 \quad 0.138$

$0.992 \quad 0.563$

$0.941 \quad 0.001$

$0.999 \quad 0.904$

$0.970 \quad 0.005$

$\begin{array}{ll}1.000 & - \\ 0.971 & 0.010\end{array}$

$0.995 \quad 0.691$

$0.985 \quad 0.093$

$0.995 \quad 0.632$

$0.973 \quad 0.001$

$0.983 \quad 0.081$

$0.965 \quad 0.010$

1.000

0.953

0.970

$\begin{array}{ll}- & 1.000\end{array}$

$0.132 \quad 0.950$

0.115

$0.247 \quad 0.968$

0.220

$0.601 \quad 1.011$

0.705

$\begin{array}{lll}0.101 & 0.951 & 0.066\end{array}$

0.956

$0.057 \quad 0.917$

0.092

$\begin{array}{lll}0.892 & 1.011 \quad 0.834\end{array}$

1.007

0.982

$0.000 \quad 0.981$

0.000

$\begin{array}{lll}0.000 & 1.001 & 0.000\end{array}$ 
Table 2 Discrete-time hazard model of mortality at ages $30+$, continued

$\underline{\text { Variable }}$

Period:

1842-59 (ref.)

1860-64

1865-69

1870-74

1875-79

1880-84

1885-89

1890-94

1895-99

1900-04

1905-09

1910-14

1915-19

1920-24

1925-29

1930-34

1935-39

1940-44

1945-49

1950-54

1955-59

1960-64

1965-69

1970-74

1975-79

1980-84

1985-89

1990-94

1995-99

2000-04

2005-13

-2Log Likelihood

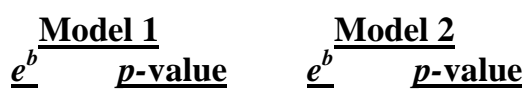

$\begin{array}{lccc}1.000 & - & 1.000 & - \\ 0.756 & 0.259 & 0.754 & 0.255 \\ 0.847 & 0.447 & 0.845 & 0.439 \\ 0.658 & 0.053 & 0.656 & 0.051 \\ 0.643 & 0.030 & 0.641 & 0.029 \\ 0.467 & 0.000 & 0.466 & 0.000 \\ 0.475 & 0.000 & 0.474 & 0.000 \\ 0.549 & 0.001 & 0.547 & 0.001 \\ 0.441 & 0.000 & 0.444 & 0.000 \\ 0.439 & 0.000 & 0.445 & 0.000 \\ 0.391 & 0.000 & 0.398 & 0.000 \\ 0.351 & 0.000 & 0.358 & 0.000 \\ 0.423 & 0.000 & 0.434 & 0.000 \\ 0.328 & 0.000 & 0.339 & 0.000 \\ 0.342 & 0.000 & 0.354 & 0.000 \\ 0.336 & 0.000 & 0.349 & 0.000 \\ 0.329 & 0.000 & 0.343 & 0.000 \\ 0.414 & 0.000 & 0.433 & 0.000 \\ 0.367 & 0.000 & 0.385 & 0.000 \\ 0.339 & 0.000 & 0.355 & 0.000 \\ 0.314 & 0.000 & 0.328 & 0.000 \\ 0.290 & 0.000 & 0.302 & 0.000 \\ 0.312 & 0.000 & 0.324 & 0.000 \\ 0.295 & 0.000 & 0.305 & 0.000 \\ 0.310 & 0.000 & 0.320 & 0.000 \\ 0.298 & 0.000 & 0.308 & 0.000 \\ 0.271 & 0.000 & 0.279 & 0.000 \\ 0.307 & 0.000 & 0.315 & 0.000 \\ 0.336 & 0.000 & 0.345 & 0.000 \\ 0.368 & 0.000 & 0.378 & 0.000 \\ 0.568 & 0.001 & 0.584 & 0.046\end{array}$

108585.503 
Table 3 Discrete-time hazard model of mortality at ages 30+: Dutch men born in 1812-1921

Variable

Early-life conditions:

$\begin{array}{ccccc}\text { Height } & 0.996 & 0.047 & 0.996 & 0.037 \\ { }_{1} \mathrm{q}_{0} \times 100 & 1.000 & 0.967 & 0.999 & 0.919 \\ { }_{4} \mathrm{q}_{1} \times 100 & 1.004 & 0.490 & 1.005 & 0.561\end{array}$

Place of birth:

Friesland

Groningen

Drenthe

Overijssel

Gelderland

Utrecht (ref.)

North Holland

Amsterdam

South Holland

Rotterdam

Zeeland

North Brabant

Limburg

Interaction of ${ }_{4} \mathrm{q}_{1}$ with place of birth:

Friesland

Groningen

Drenthe

Overijssel

Gelderland

Utrecht (ref.)

North Holland

Amsterdam

South Holland

Rotterdam

Zeeland

North Brabant

Limburg

Socio-economic status of father:

Unskilled workers (ref.)

Semi-skilled workers

Skilled workers

Farmers

Middle-class

$$
\text { Elite }
$$

Unknown

Age (linear)

Age (quadratic)
Model 1

$\begin{array}{lccc}0.873 & 0.001 & 0.858 & 0.112 \\ 0.830 & 0.000 & 1.204 & 0.178 \\ 0.903 & 0.109 & 1.035 & 0.840 \\ 1.034 & 0.451 & 0.983 & 0.866 \\ 0.891 & 0.009 & 1.104 & 0.358 \\ 1.000 & - & 1.000 & - \\ 0.860 & 0.001 & 0.790 & 0.042 \\ 0.997 & 0.957 & 0.984 & 0.895 \\ 0.869 & 0.001 & 0.917 & 0.042 \\ 0.974 & 0.643 & 0.822 & 0.103 \\ 0.810 & 0.000 & 0.781 & 0.021 \\ 0.943 & 0.190 & 0.967 & 0.758 \\ 0.948 & 0.318 & 1.099 & 0.478\end{array}$

$1.001 \quad 0.858$

$0.958 \quad 0.003$

$0.984 \quad 0.364$

$1.004 \quad 0.613$

$0.976 \quad 0.019$

1.000 -

$1.009 \quad 0.418$

$1.001 \quad 0.913$

$0.993 \quad 0.487$

$1.017 \quad 0.099$

$1.003 \quad 0.724$

$0.997 \quad 0.757$

$0.982 \quad 0.199$

$\begin{array}{lccc}1.000 & - & 1.000 & - \\ 0.960 & 0.213 & 0.958 & 0.192 \\ 1.017 & 0.531 & 1.016 & 0.569 \\ 0.887 & 0.000 & 0.887 & 0.000 \\ 1.041 & 0.142 & 1.037 & 0.186 \\ 0.994 & 0.901 & 1.017 & 0.752 \\ 1.101 & 0.056 & 1.103 & 0.051 \\ & & & \\ 1.023 & 0.000 & 1.021 & 0.000 \\ 1.000 & 0.000 & 1.000 & 0.000\end{array}$


Table 3 Discrete-time hazard model of mortality at ages 30+, continued

$\underline{\text { Variable }}$

Period:

1842-59 (ref.)

1860-64

1865-69

1870-74

1875-79

1880-84

1885-89

1890-94

1895-99

1900-04

1905-09

1910-14

1915-19

1920-24

1925-29

1930-34

1935-39

1940-44

1945-49

1950-54

1955-59

1960-64

1965-69

1970-74

1975-79

1980-84

1985-89

1990-94

1995-99

2000-04

2005-13

-2Log Likelihood

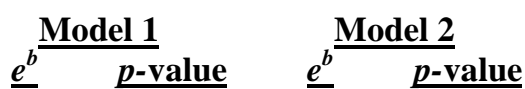

$\begin{array}{lccc}1.000 & - & 1.000 & - \\ 0.749 & 0.217 & 0.750 & 0.219 \\ 0.609 & 0.027 & 0.611 & 0.027 \\ 0.587 & 0.010 & 0.588 & 0.010 \\ 0.524 & 0.001 & 0.523 & 0.001 \\ 0.501 & 0.000 & 0.500 & 0.000 \\ 0.416 & 0.000 & 0.415 & 0.000 \\ 0.378 & 0.000 & 0.376 & 0.000 \\ 0.358 & 0.000 & 0.359 & 0.000 \\ 0.349 & 0.000 & 0.350 & 0.000 \\ 0.332 & 0.000 & 0.334 & 0.000 \\ 0.321 & 0.000 & 0.324 & 0.000 \\ 0.346 & 0.000 & 0.350 & 0.000 \\ 0.287 & 0.000 & 0.292 & 0.000 \\ 0.279 & 0.000 & 0.285 & 0.000 \\ 0.244 & 0.000 & 0.252 & 0.000 \\ 0.250 & 0.000 & 0.258 & 0.000 \\ 0.332 & 0.000 & 0.344 & 0.000 \\ 0.284 & 0.000 & 0.294 & 0.000 \\ 0.253 & 0.000 & 0.262 & 0.000 \\ 0.269 & 0.000 & 0.278 & 0.000 \\ 0.261 & 0.000 & 0.269 & 0.000 \\ 0.307 & 0.000 & 0.315 & 0.000 \\ 0.309 & 0.000 & 0.316 & 0.000 \\ 0.312 & 0.000 & 0.318 & 0.000 \\ 0.306 & 0.000 & 0.311 & 0.000 \\ 0.297 & 0.000 & 0.301 & 0.000 \\ 0.331 & 0.000 & 0.335 & 0.000 \\ 0.338 & 0.000 & 0.342 & 0.000 \\ 0.338 & 0.000 & 0.342 & 0.000 \\ 0.407 & 0.004 & 0.411 & 0.001\end{array}$

106604.508

106576.690 


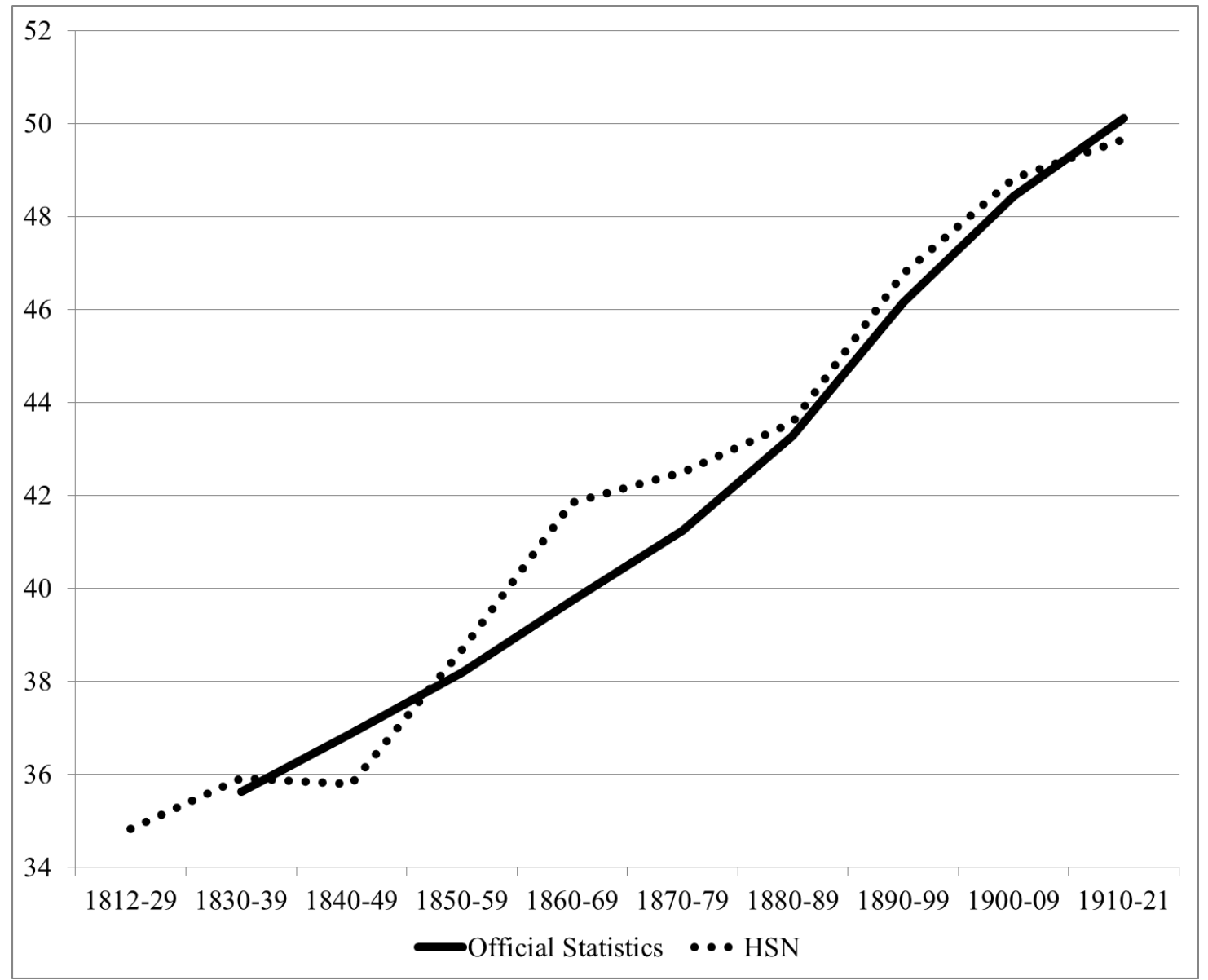

Figure 1 Cohort life expectancy at age 30 in the HSN and official statistics: Women.

Source: HSN and unpublished cohort life tables constructed by Statistics Netherlands. 


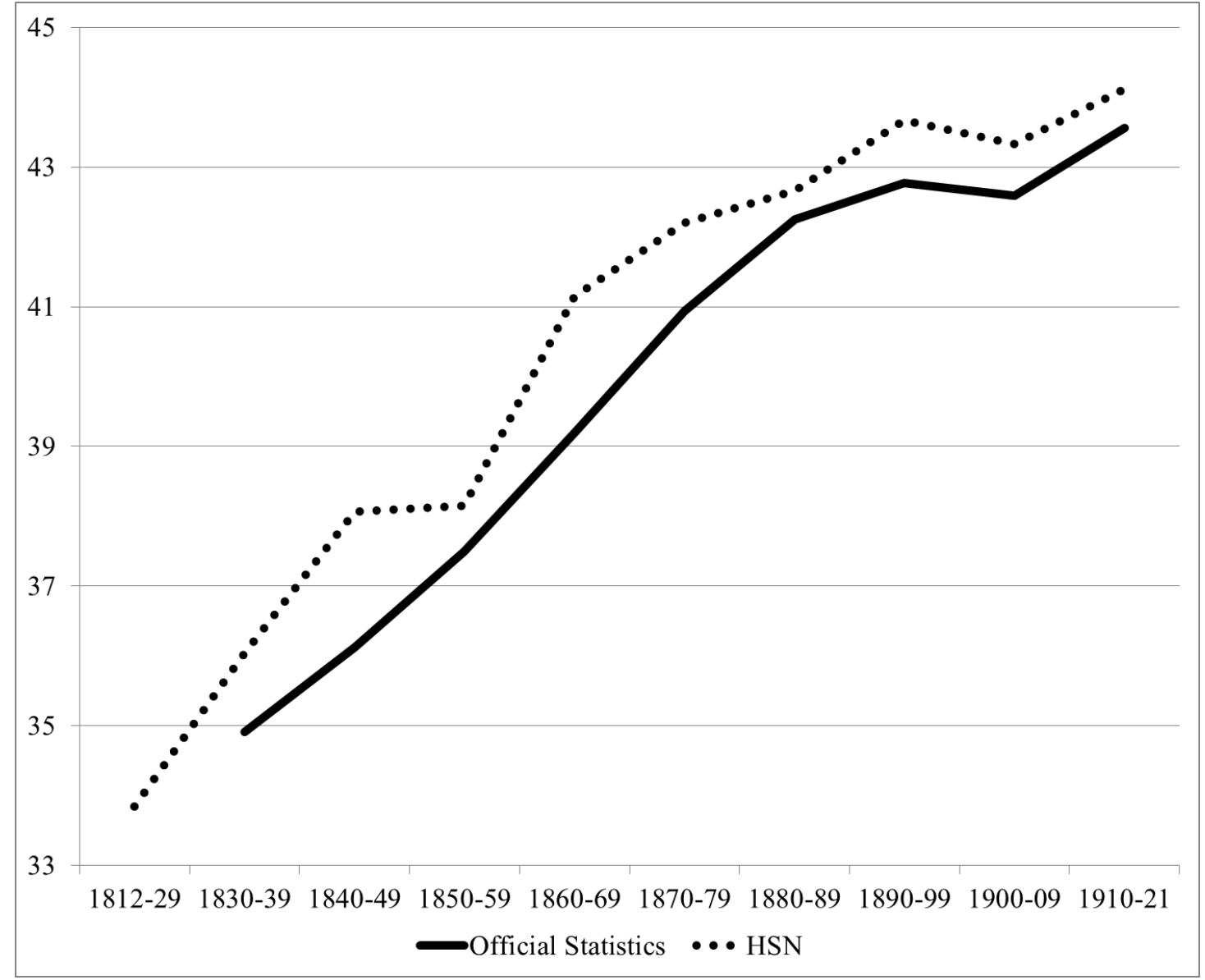

Figure 2 Cohort life expectancy at age 30 in the HSN and official statistics: Men.

Source: HSN and unpublished cohort life tables constructed by Statistics Netherlands. 


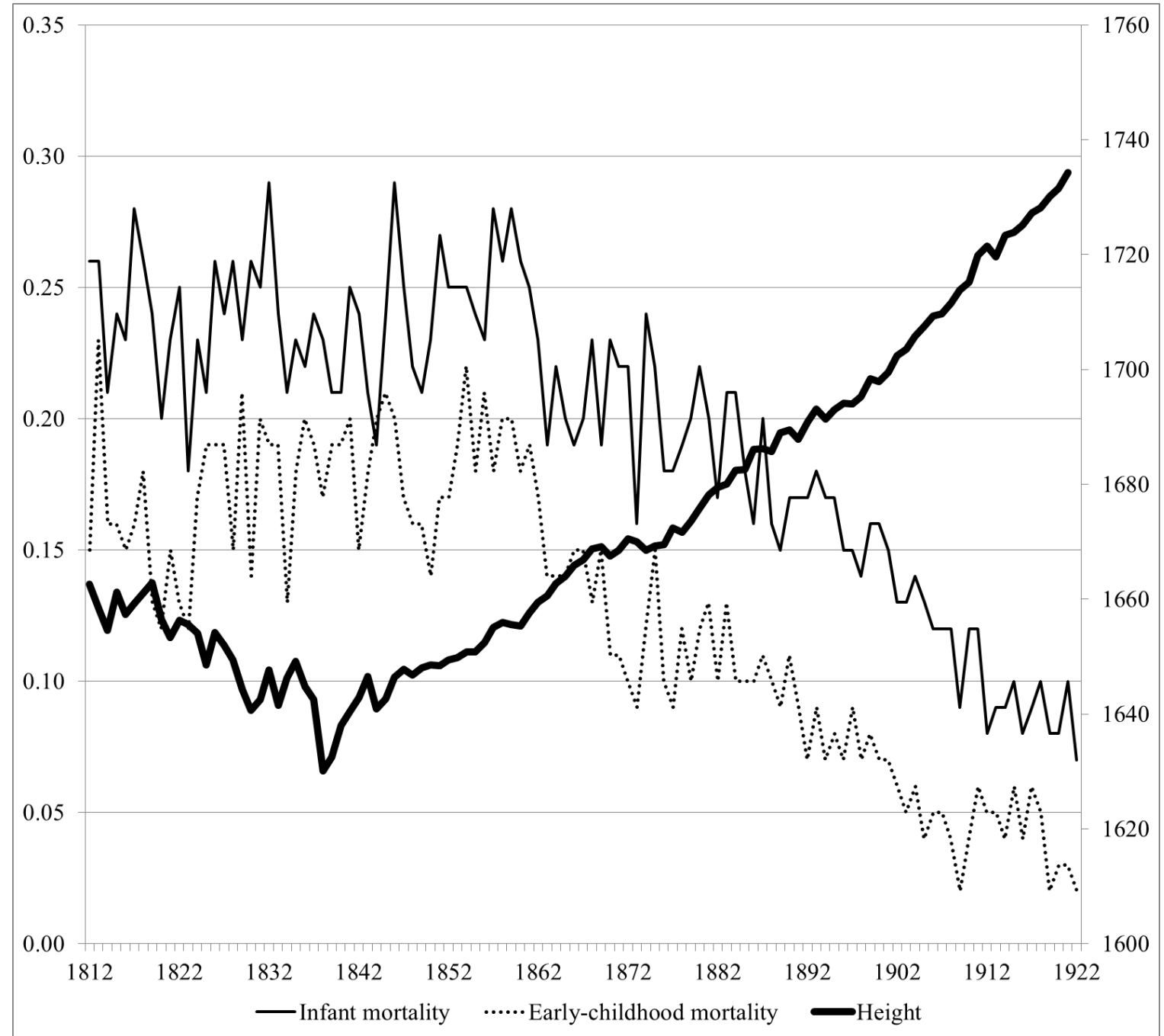

Figure 3 Infant mortality $\left({ }_{1} \mathrm{q}_{0}\right)$, early-childhood mortality $\left({ }_{4} \mathrm{q}_{1}\right)$ and height of conscripts in mm by year of birth (right $\mathrm{Y}$-axis) by year of birth, the Netherlands $1812-1922$.

Source: HSN Data Set Life Courses Release 2013.01; Mandemakers and van Zanden (1993) and Drukker and Tassenaar (1997). 


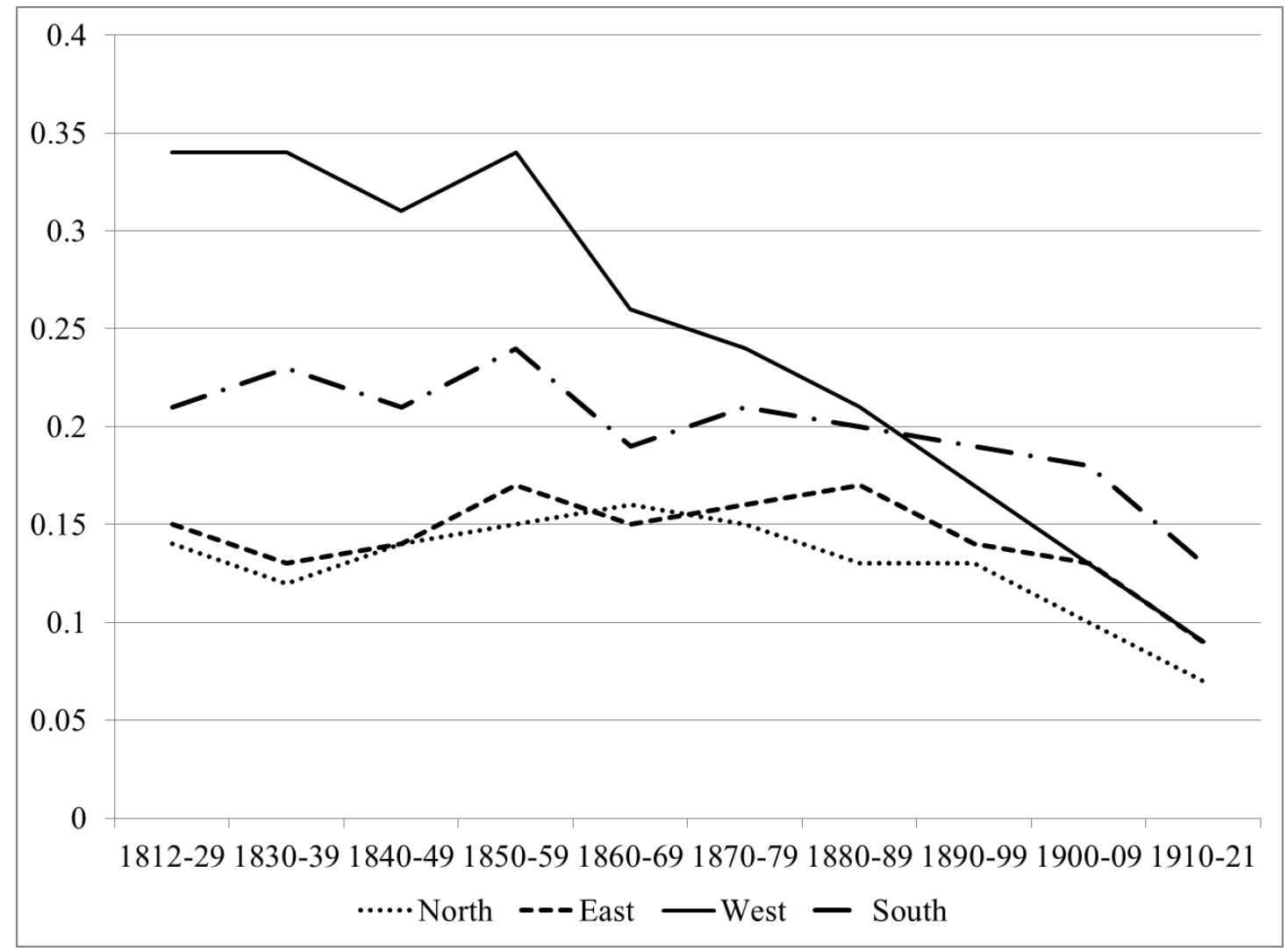

Figure 4(a) Infant mortality $\left({ }_{1} \mathrm{q}_{0}\right)$ by birth cohort and region, the Netherlands 18121921.

Source: HSN Data Set Life Courses Release 2013.01. 


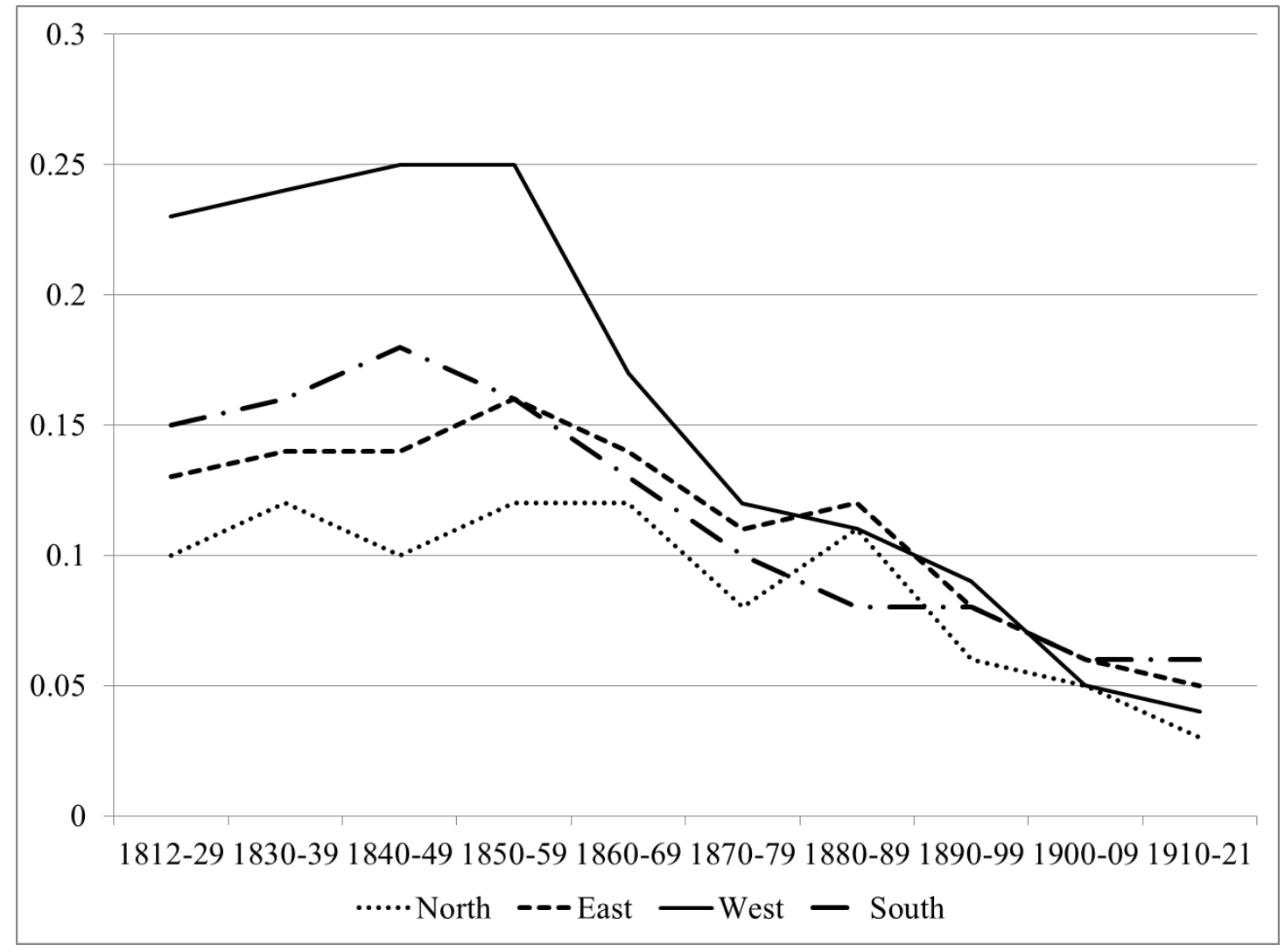

Figure 4(b) Early-childhood mortality $\left({ }_{4} \mathrm{q}_{1}\right)$ by birth cohort and region, the Netherlands 1812-1921.

Source: HSN Data Set Life Courses Release 2013.01. 


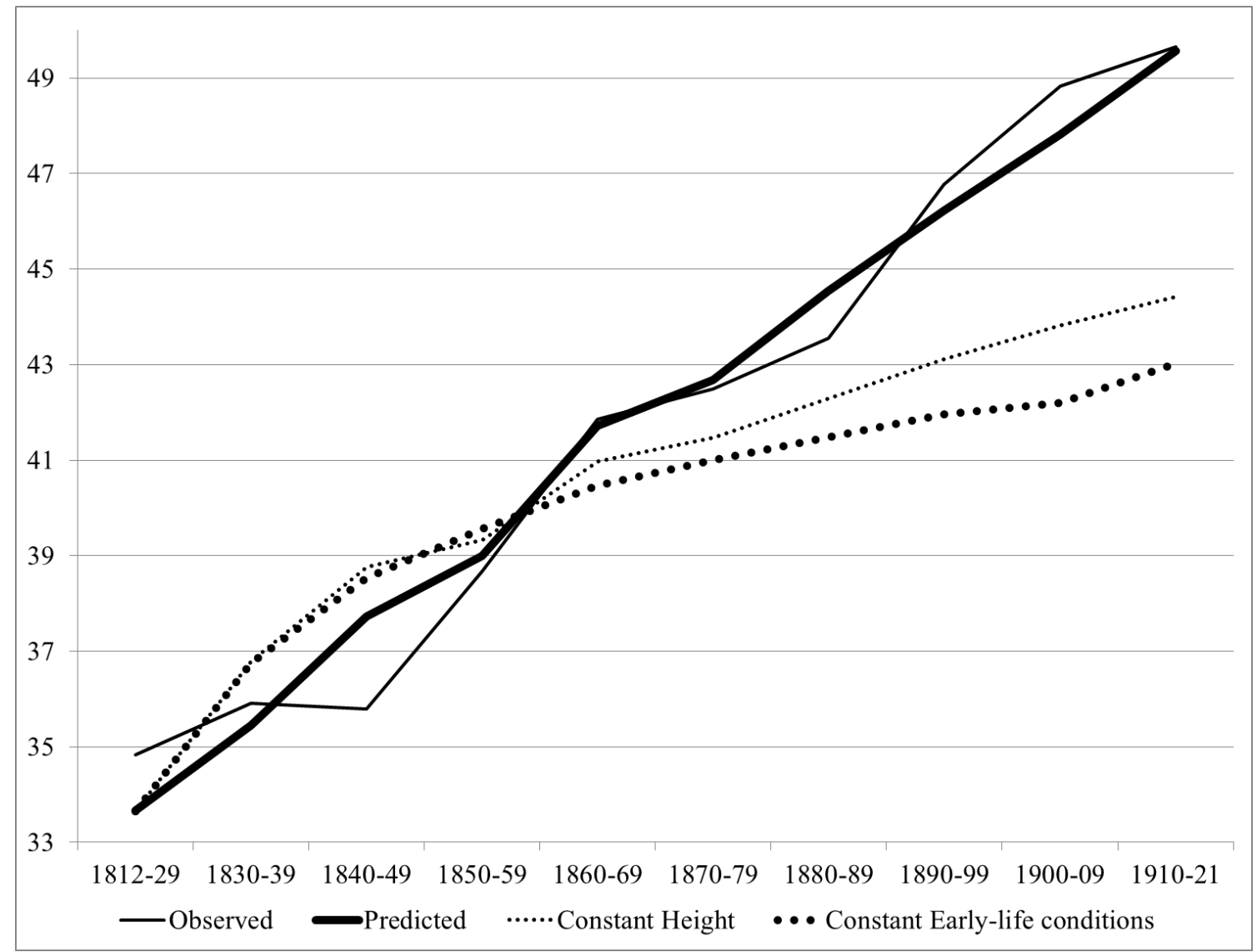

Figure 5 Observed, predicted and counterfactual predicted ("constant height" and "constant early-life conditions") values of cohort life expectancy at age 30 in the HSN: Women.

Source: Second model in Table 2. 


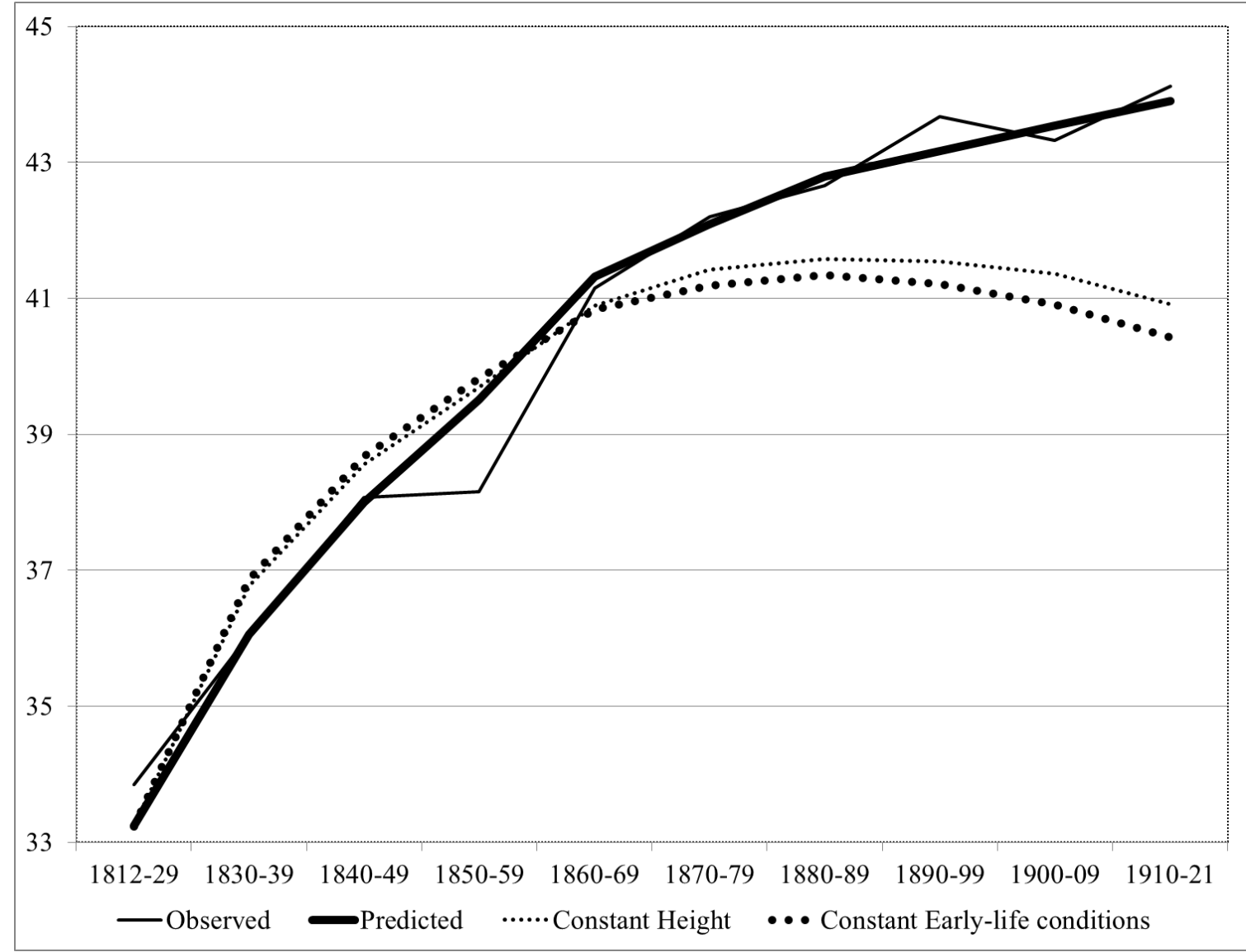

Figure 6 Observed, predicted and counterfactual predicted ("constant height" and "constant early-life conditions") values of cohort life expectancy at age 30 in the HSN: Men.

Source: Second model in Table 3. 